\title{
Directed Evolution and Substrate Specificity Profile of Homing Endonuclease I-SceI
}

\author{
Jeffrey B. Doyon, Vikram Pattanayak, Carissa B. Meyer, and David R. Liu
}

\section{Supporting Information}

A.

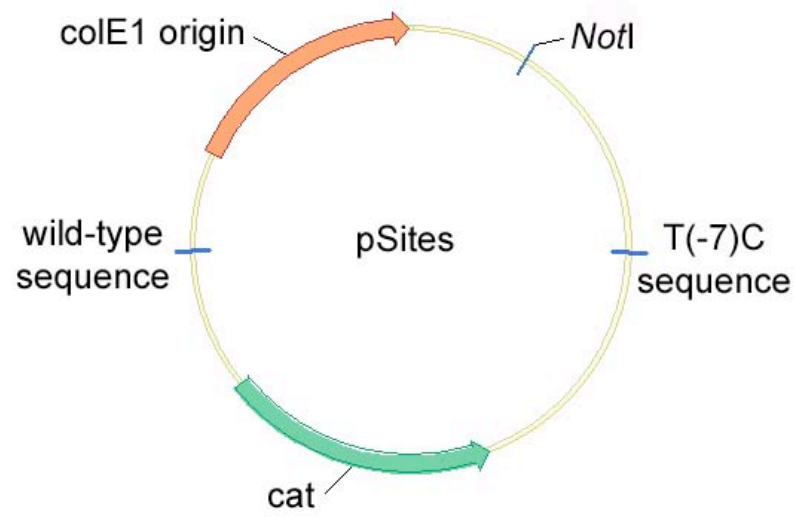

B.
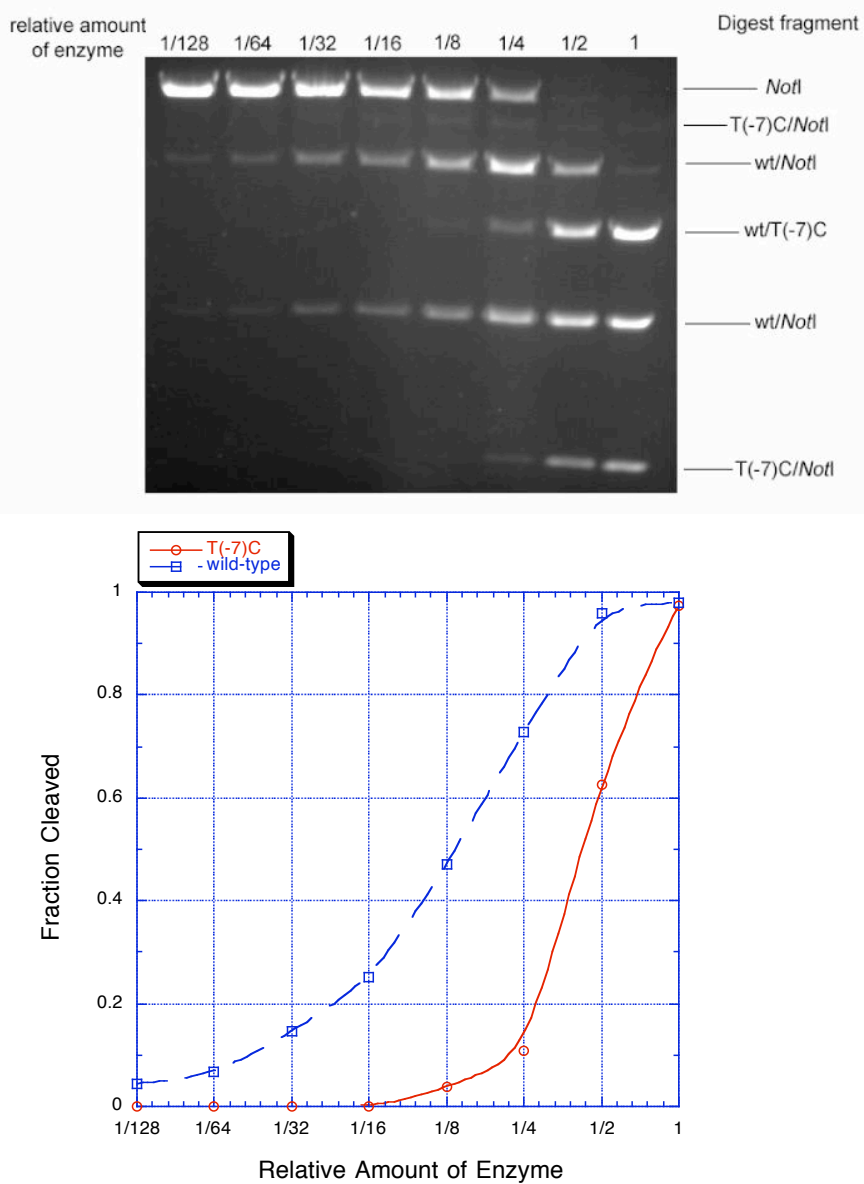

Figure S1. In vitro competition assay for endonuclease activity. (A) A plasmid, pSites, containing one copy of each the wild-type and T(-7)C cleavage sites of I-SceI was used as a substrate for an in vitro cleavage assay for endonuclease activity. (B) Two-fold dilutions of purified I-SceI were each added to $100 \mathrm{ng}$ of pSites and were incubated at $37{ }^{\circ} \mathrm{C}$ for $20 \mathrm{~min}$. The digests were quenched, then digested with NotI, and analyzed by gel electrophoresis to determine the relative amount of enzyme required to digest $50 \%$ of each site using KALEIDAGRAPH. 